\title{
(2) OPEN ACCESS \\ Early versus later initiation of parenteral nutrition for very preterm infants: a propensity score-matched observational study
}

\author{
Sabita Uthaya 조 , Nicholas Longford, Cheryl Battersby, Kayleigh Oughham, \\ Julia Lanoue, Neena Modi
}

\begin{abstract}
- Additional supplemental material is published online only. To view, please visit the journal online (http://dx.doi. org/10.1136/archdischild2021-322383)
\end{abstract}

Department of Neonatal Medicine, Imperial College London, London, UK

Correspondence to Dr Sabita Uthaya, Neonatal Medicine, Imperial College London, London, UK: s.uthaya@imperial.ac.uk

Received 4 May 2021 Accepted 8 October 2021

\section{Linked}

- http://dx.doi.org/10.1136/ fetalneonatal-2021-321643 - http://dx.doi.org/10.1136/ fetalneonatal-2021-323072

\section{Check for updates}

(C) Author(s) (or their employer(s)) 2021. Re-use permitted under CC BY-NC. No commercial re-use. See rights and permissions. Published by BMJ.

To cite: Uthaya S, Longford N, Battersby C, et al. Arch Dis Child Fetal Neonatal Ed Epub ahead of print: [please include Day Month Year]. doi:10.1136/archdischild 2021-322383

\begin{abstract}
Objective To evaluate the impact of timing of initiation of parenteral nutrition (PN) after birth in very preterm infants.

Design Propensity-matched analysis of data from the UK National Neonatal Research Database.

Patients 65033 babies <31 weeks gestation admitted to neonatal units in England and Wales between 2008 and 2019.

Interventions PN initiated in the first 2 days (early) versus after the second postnatal day (late). Babies who died in the first 2 days without receiving PN were analysed as 'late'.
\end{abstract}

Main outcome measures The main outcome measure was morbidity-free survival to discharge. The secondary outcomes were survival to discharge, growth and other core neonatal outcomes.

Findings No difference was found in the primary outcome (absolute rate difference (ARD) between early and late $0.50 \%, 95 \% \mathrm{Cl}-0.45$ to $1.45, \mathrm{p}=0.29)$. The early group had higher rates of survival to discharge (ARD 3.3\%, 95\% Cl 2.7 to 3.8, $p<0.001$ ), late-onset sepsis (ARD 0.84\%, 95\% Cl 0.48 to 1.2, p<0.001), bronchopulmonary dysplasia (ARD 1.24\%, 95\% Cl 0.30 to $2.17, p=0.01)$, treated retinopathy of prematurity (ARD 0.50\%, 95\% Cl 0.17 to $0.84, p<0.001$ ), surgical procedures (ARD $0.80 \%, 95 \% \mathrm{Cl} 0.20$ to $1.40, p=0.01$ ) and greater drop in weight z-score between birth and discharge (absolute difference $0.019,95 \% \mathrm{Cl} 0.003$ to $0.035, p=0.02)$. Of $4.9 \%$ of babies who died in the first 2 days, $3.4 \%$ were in the late group and not exposed to PN.

Conclusions Residual confounding and survival bias cannot be excluded and justify the need for a randomised controlled trial powered to detect differences in important functional outcomes.

\section{BACKGROUND}

Current practice is to commence parenteral nutrition $(\mathrm{PN})$ in very preterm infants within hours of birth. ${ }^{1}$ This practice has evolved over the last decade due to concern that delayed PN places babies at risk of cumulative nutritional deficits, suboptimal growth and long-term neurodevelopmental impairment. ${ }^{23}$ Previously initiation of PN was delayed to a few days after birth due to concerns about the metabolic tolerance of very preterm infants. The safety of earlier PN initiation has not been evaluated, with all studies focusing on short-term growth measures. ${ }^{4} \mathrm{~A}$ meta-analysis that included studies of early versus

\section{What is already known on this topic?}

- Recent trials in term infants, children and adults have shown evidence of short-term and longterm harms from early initiation of parenteral nutrition (PN) in intensive care.

- A meta-analysis published in 2013 of small observational and randomised controlled trials showed short-term benefit for growth outcomes from commencing PN early in preterm infants.

- We replicated the search strategy used in this meta-analysis on 2 April 2021 and found no additional eligible studies.

\section{What this study adds?}

- In this large, whole-population, propensitymatched observational study we found no differences in survival to discharge without major morbidity comparing early versus late initiation of PN.

- We found higher rate of survival in early PN group and also higher rates of major morbidities that are known to be associated with neurodevelopmental impairment.

- We cannot exclude residual confounding related to survival bias or how sick or unstable a baby was at the time of clinical decision-making about PN initiation.

late introduction of parenteral amino acids found no differences in short-term growth or clinical outcomes nor neurodevelopmental outcomes at age 2 years. Nitrogen balance was found to be significantly different, with positive balance in the early amino acid group. ${ }^{5}$

Recent high-quality randomised controlled trials in critically ill adults and children, including fullterm infants, have shown evidence of harm from early use of PN, with adverse effects on sepsis, duration of mechanical ventilation and hospital stay, renal replacement therapy, liver function, and healthcare costs, but not on survival. ${ }^{6-10}$ Of concern are reports of the long-term adverse impact on neurocognition and behaviour in children who received early PN. ${ }^{11} 12$ These reports are supported by mechanistic studies suggesting that the developing brain is susceptible to long-term harm from 
early PN, with differential methylation of genes involved in brain development present as early as 3 days after initiation of PN. ${ }^{13-15}$

We therefore aimed to evaluate the association between timing of initiation of PN and outcomes to discharge from neonatal care in infants born below 31 weeks gestation.

\section{METHODS}

\section{Population and setting}

We included all preterm infants born below 31 weeks gestation who were admitted to and received all their care in National Health Service (NHS) neonatal units in England and Wales during the 12-year period between 1 January 2008 and 31 December 2019. We excluded infants with major congenital gastrointestinal malformations, congenital conditions requiring surgery in the neonatal period, those with life-limiting conditions (defined in online online supplemental etable 1) and for whom key background or primary outcome data were missing.

\section{Data source}

We used data held in the UK National Neonatal Research Database (NNRD). ${ }^{16}$ It contains quality-assured data (the Neonatal Data Set, an NHS Information Standard; Standardisation Committee for Care Information 1595) extracted at regular intervals from the electronic patient records of infants admitted to UK neonatal units from 2007 to the present. The NNRD is a national data asset discoverable through the Health Data Research UK Alliance Innovation Gateway (https://www.healthdatagateway.org/) and is available for use by external investigators. A formal test of NNRD data quality showed less than 5\% discordance with equivalent items collected independently for a trial funded by the National Institute for Health Research and performed to Good Clinical Practice standards. ${ }^{17}$ All neonatal units agreed to the inclusion of their data in the study.

\section{Exposures}

PN initiated in the first 2 days after birth (early) versus after the second postnatal day (late) was evaluated. Each day in the NNRD is recorded as the time between two consecutive midnights and not from the time of birth of the infant. Depending on the time of birth early PN could reflect the time of initiation of PN from within 1 hour to 48 hours of birth and late PN as that commencing from 25 hours after birth. The choice of 2 postnatal days after birth to define 'early' was pragmatic, reflecting the definition in the systematic review and meta-analysis of early versus late $\mathrm{PN}$ in preterm infants. ${ }^{4}$ Babies who died in the first 2 days who did not receive PN were assigned to the late group.

\section{Outcomes}

The primary outcome was morbidity-free survival to discharge from neonatal care, defined as survival to discharge without any of the following: late-onset sepsis (defined as one or more episodes of a positive blood or cerebrospinal fluid culture with either a pure or mixed growth of a known pathogenic organism after the first 72 hours following birth), bronchopulmonary dysplasia (defined as any respiratory or ventilatory support or supplemental oxygen at 36 weeks postmenstrual age), treatment for retinopathy of prematurity (ROP) (defined as cryotherapy, laser therapy or injection of anti-vascular endothelial growth factor therapy for ROP in either or both eyes), severe necrotising enterocolitis (defined as necrotising enterocolitis resulting in surgery or confirmed at surgery ${ }^{18}$ ), seizures and severe brain injury (defined as either left or right grade 3 or higher intraventricular haemorrhage or periventricular leucomalacia). The secondary outcome measures included all these morbidities and survival to discharge from neonatal care, 'any' necrotising enterocolitis (defined as any treatment for necrotising enterocolitis or diagnosis of necrotising enterocolitis and 5 or more consecutive days recorded as being nil by mouth and in receipt of antibiotics), weight gain (defined as change in weight z-score between birth and discharge), surgical procedures (defined as any major surgical procedure recorded during neonatal admission) and maximum stage of ROP in either eye (ranging from no ROP to stage 1-5 or aggressive posterior ROP). Long-term outcomes included neuromotor, auditory and visual impairment at age 2 years corrected for prematurity.

\section{Statistical analysis}

We used propensity score matching to compare the outcomes between the early and the late PN group. The propensity score is the probability of treatment assignment conditional on observed baseline characteristics and is derived using logistic regression. Propensity score matching entails forming matched sets of treated and untreated participants who share similar values of the propensity score, resulting in the formation of a cohort in which the two treatment groups have similar baseline characteristics as would be the case in a randomised controlled trial.

Infants were assigned to groups based on three principal background variables: year of birth, gestation and multiplicity. The principal background groups were defined by 3 birth year groups (4 consecutive years in each group), 3 gestational age groups (23-25, 26-27 and 28-30 weeks) and 2 groups based on multiplicity (singleton and multiple birth), resulting in 18 groups. Adaptive splitting of each of the groups based on the propensity score was used to create strata of infants. In each stratum, the two treatment groups had similar average propensities. Inverse probability weighting was used to arrange a balance of the two groups. Thus, every infant with unexceptional propensity score contributed to the analysis, although many of them with small weights. The weight each baby contributed to the analysis was inversely proportional to their propensity score; the resulting matched cohort therefore has a smaller effective size than the unmatched cohort.

To demonstrate that the groups were well matched, we assessed the balance of all the background variables by evaluating the scaled differences of the means or proportions within the two treatment groups. The scaling was accomplished by dividing the difference by the pooled SD of the background variable. We aimed for each of these differences to be below 0.1 in absolute value, following Imbens and Rubin, ${ }^{19}$ and the average of these absolute balances below 0.05 . We obtained scaled differences ranging from -0.014 to 0.011 , satisfying these criteria by a wide margin. The mean of the absolute values of the balance was 0.0044 , whereas the mean before matching was 0.134 (online supplemental efigure 1).

We compared the means and proportions of the two treatment groups, early minus late PN by means of a t-test, and the median by a permutation test. Analyses were carried out using R V.3.3.0.

\section{RESULTS}

There were 69733 infants born below 31 weeks of gestation between 1 January 2008 and 31 December 2019 who were admitted to and received all of their care in neonatal units in England and Wales. After exclusions, as shown in figure 1, and the application of inverse probability weighting, there were 8147 matched pairs, a cohort of 16294 infants. Key baseline characteristics are shown in table 1 . The number of babies in each of 
Original research

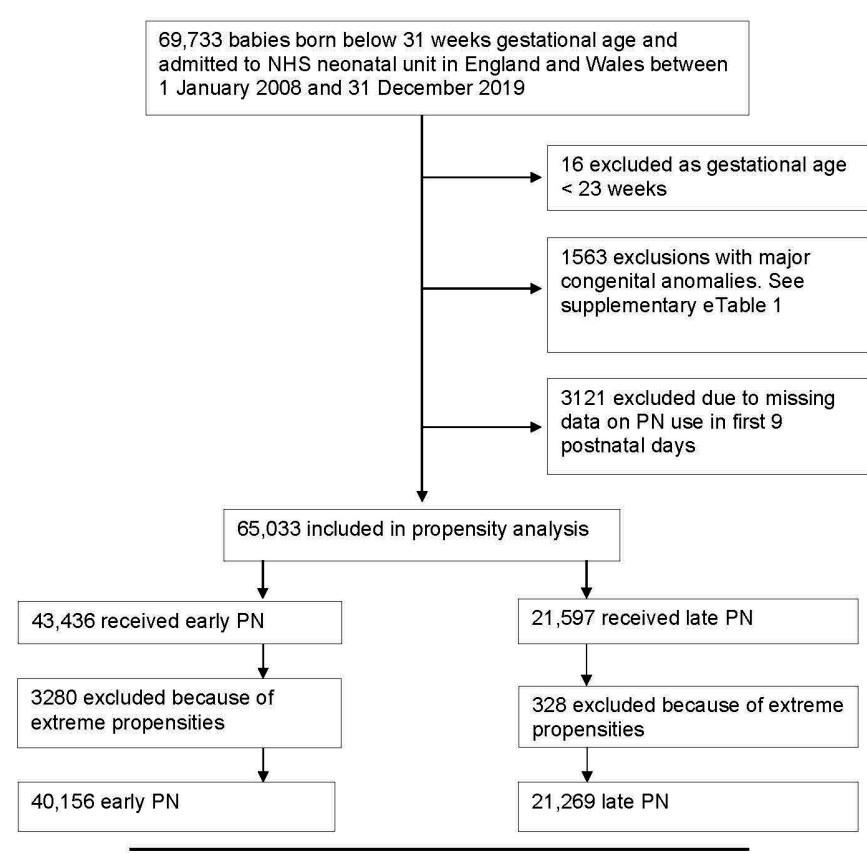

Application of inverse probability weighting to all included babies with effective sample size of $16,294(2 \times 8147)$

Figure 1 Study cohort. NHS, National health Service; PN, parenteral nutrition.

the three groups based on the three principal background variables is shown in online supplemental etable 3 .

Table 2 shows the outcomes. All comparisons refer to the difference of early minus late PN. There was no evidence of difference in the primary outcome of survival to discharge without major morbidity: percentage (SE), early $59.50(0.30)$ and late $59.03(0.36)$ (absolute rate difference: early versus late $\mathrm{PN}-0.50 \%, 95 \% \mathrm{CI}-0.45$ to $1.45, \mathrm{p}=0.294)$. The rate of survival to discharge was significantly higher in infants who received early PN. Infants who received early PN also had significantly higher rates of late-onset sepsis, bronchopulmonary dysplasia, treatment for ROP, stage 3 or higher ROP, surgical procedures and greater drop in weight $\mathrm{z}$-score between birth and discharge. We found no significant differences in the rates of severe or 'any' necrotising enterocolitis, seizures, major brain injury or outcomes at age 2 years corrected for prematurity. Among infants who died, the median age (days) at death was higher in the early group. Of $4.9 \%$ of babies who died in the first 2 days, 3.4\% were assigned to the late group as they did not receive PN. After the second day there were more deaths in the early group (online supplemental etable 2).

\section{DISCUSSION}

In this large, population-wide, observational study of early versus later introduction of PN in very preterm infants, we found evidence of lower mortality in the group who received early PN, but also higher rates of morbidity.

The finding of increased mortality in the late group is out of keeping with the outcomes in adults and children comparing early versus late PN. ${ }^{67}$ We speculate that the reasons for this could be twofold. First, babies who died in the first 2 days who never received PN were analysed in the late group. In effect $3.4 \%$ of babies in the late group (compared with $1.5 \%$ in the early) died before meeting our definition of late PN, which
Table 1 Key background characteristics

\begin{tabular}{|c|c|c|c|c|}
\hline & \multicolumn{2}{|l|}{ Entire cohort } & \multicolumn{2}{|c|}{ Matched cohort } \\
\hline & $\begin{array}{l}\text { Early PN } \\
(n=43436)\end{array}$ & $\begin{array}{l}\text { Late PN } \\
(n=21597)\end{array}$ & $\begin{array}{l}\text { Early PN } \\
(n=8147)\end{array}$ & $\begin{array}{l}\text { Late PN } \\
(n=8147)\end{array}$ \\
\hline \multicolumn{5}{|c|}{ Infant characteristics at birth } \\
\hline $\begin{array}{l}\text { Gestational age } \\
\text { (weeks), mean (SD) }\end{array}$ & $27.7(2.0)$ & $28.9(2.0)$ & $28.5(2.0)$ & $28.5(2.0)$ \\
\hline $\begin{array}{l}\text { Birth weight }(\mathrm{kg}) \text {, } \\
\text { mean }(\mathrm{SD})\end{array}$ & $1.02(0.303)$ & $1.22(0.342)$ & $1.14(0.322)$ & $1.15(0.32)$ \\
\hline $\begin{array}{l}\text { Birth weight z-score, } \\
\text { mean (SD) }\end{array}$ & $-0.08(0.99)$ & $0.16(0.93)$ & $0.06(0.96)$ & $0.06(0.93)$ \\
\hline Girls, n (\%) & $19880(46.3)$ & $9385(44.8)$ & $3633(45.7)$ & $3633(45.7)$ \\
\hline \multicolumn{5}{|l|}{ Maternal factors } \\
\hline $\begin{array}{l}\text { Maternal age, mean } \\
\text { (SD) }\end{array}$ & $30.5(6.3)$ & $30.1(6.3)$ & $30.3(6.4)$ & $30.3(6.3)$ \\
\hline $\begin{array}{l}\text { Maternal diabetes, } \\
\mathrm{n}(\%)\end{array}$ & $624(1.4)$ & $249(1.2)$ & $108(1.3)$ & $102(1.3)$ \\
\hline $\begin{array}{l}\text { Maternal gestational } \\
\text { diabetes, } \mathrm{n}(\%)\end{array}$ & $1172(2.7)$ & $678(3.1)$ & $489(3.0)$ & $496(3.0)$ \\
\hline $\begin{array}{l}\text { Maternal gestational } \\
\text { hypertension, } \mathrm{n}(\%)\end{array}$ & $3167(7.3)$ & $1759(8.1)$ & $692(8.5)$ & $704(8.6)$ \\
\hline $\begin{array}{l}\text { Maternal pre- } \\
\text { eclampsia, n }(\%)\end{array}$ & $1973(4.5)$ & $529(2.5)$ & $232(2.8)$ & $242(3.0)$ \\
\hline $\begin{array}{l}\text { Prolonged rupture of } \\
\text { membranes, } \mathrm{n}(\%)\end{array}$ & $4715(10.9)$ & $2633(12.2)$ & $957(11.8)$ & $946(11.6)$ \\
\hline $\begin{array}{l}\text { Chorioamnionitis, } \\
\mathrm{n}(\%)\end{array}$ & $3019(8.3)$ & $1200(7.2)$ & $478(7.3)$ & $472(7.3)$ \\
\hline $\begin{array}{l}\text { Complete course of } \\
\text { antenatal steroids, } \\
\mathrm{n}(\%)\end{array}$ & $29786(71.9)$ & $13736(68.9)$ & $5268(69.2)$ & $5256(69.2)$ \\
\hline \multicolumn{5}{|c|}{ Infant factors after birth } \\
\hline $\begin{array}{l}\text { Apgar score }<5 \text { at } 5 \\
\min , \mathrm{n}(\%)\end{array}$ & $5186(13.5)$ & $1837(9.6)$ & $813(11.2)$ & $794(11.0)$ \\
\hline $\begin{array}{l}\text { Intubation during } \\
\text { resuscitation, } \mathrm{n}(\%)\end{array}$ & $26752(62.0)$ & $9445(43.7)$ & $4158(51.4)$ & $4144(50.9)$ \\
\hline \multicolumn{5}{|l|}{ Infant factors on first day } \\
\hline $\begin{array}{l}\text { Ventilated on first } \\
\text { day, } \mathrm{n}(\%)\end{array}$ & $33506(77.1)$ & $12728(58.9)$ & $5460(67.0)$ & $5463(67.0)$ \\
\hline $\begin{array}{l}\text { Surfactant given, } \\
\mathrm{n}(\%)\end{array}$ & $21384(49.2)$ & $8882(41.1)$ & $3739(46.0)$ & $3740(46.0)$ \\
\hline $\begin{array}{l}\text { Inotropes on first } \\
\text { day, } \mathrm{n}(\%)\end{array}$ & $9544(22.0)$ & 3352 (15.5) & $1512(19.4)$ & $1495(18.4)$ \\
\hline $\begin{array}{l}\text { Treated for infection } \\
\text { on first day, } \mathrm{n}(\%)\end{array}$ & $25428(58.5)$ & $12323(57.6)$ & 4767 (58.5) & $4762(58.8)$ \\
\hline \multicolumn{5}{|l|}{ Organisational factors } \\
\hline $\begin{array}{l}\text { Born in level } 3 \text { unit } \\
(\mathrm{NICU}), \mathrm{n}(\%)\end{array}$ & $26790(61.7)$ & $10037(46.5)$ & $4043(49.7)$ & $4060(49.9)$ \\
\hline $\begin{array}{l}\text { Transferred on first } \\
\text { day, } n(\%)\end{array}$ & 6205 (14.3) & 2907 (13.5) & $1203(14.8)$ & $1200(14.7)$ \\
\hline
\end{tabular}

$\mathrm{NICU}$, neonatal intensive care unit; PN, parenteral nutrition.

introduces the so-called survival bias. Survival bias arises in studies that use a time window from the start of follow-up to define users of a medication or an exposure to an intervention. This introduces artificial survival advantage associated with the exposed participants regardless of the effectiveness of the treatment and is a limitation of observational studies. ${ }^{20}$ After the first 2 days, death rate was higher in the early compared with the late group. Second, decision regarding timing of initiation of PN could be confounded by the clinical condition of the baby, with later commencement in the sickest infants, who are also more likely to die. Previously commencement of PN was delayed in preterm infants due to concerns regarding metabolic tolerance. 
Table 2 Neonatal outcomes

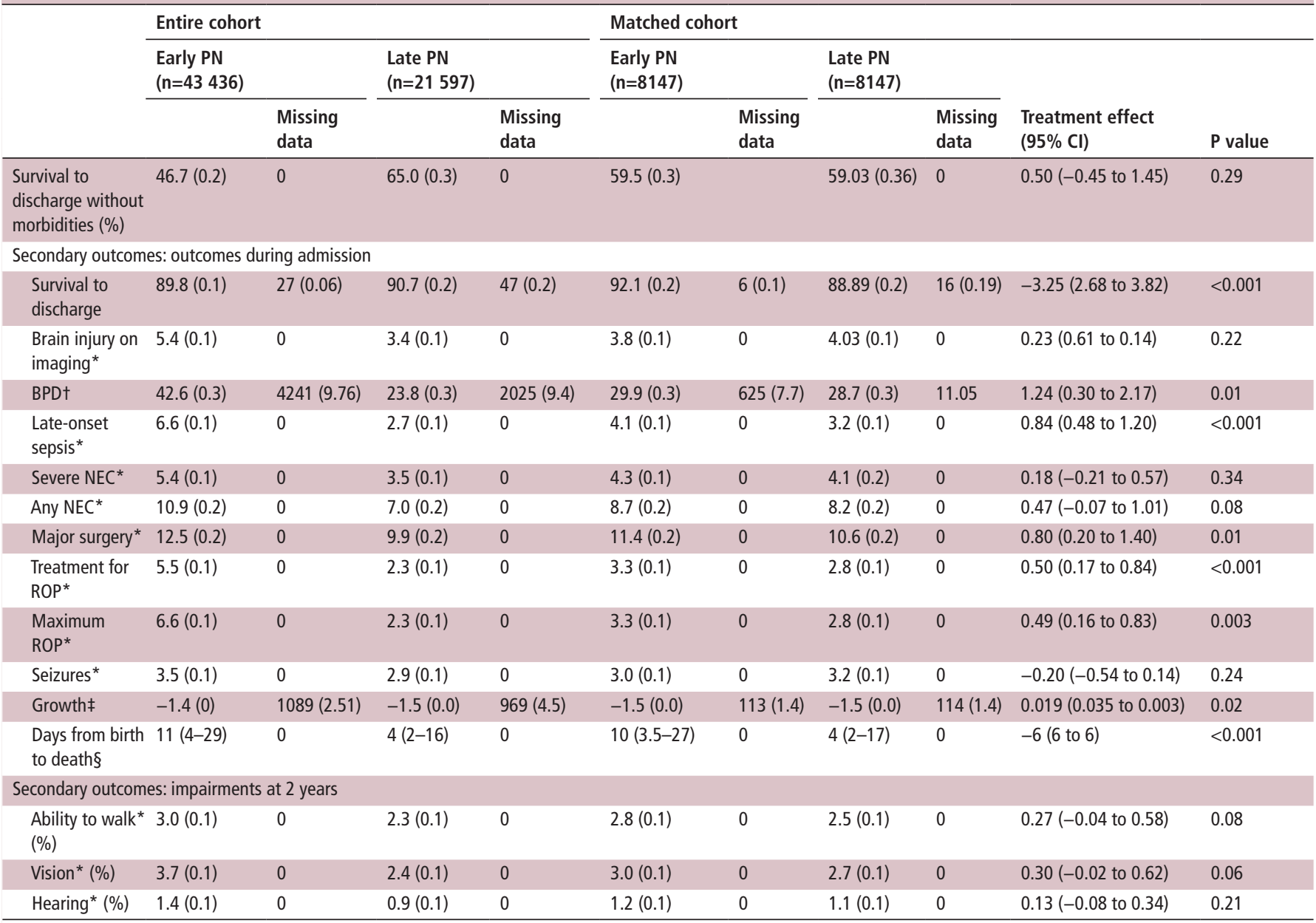

Data are percentages (SE), unless indicated otherwise.

Missing data presented as $\mathrm{n}(\%)$.

Growth is change in weight z-score between birth and discharge.

${ }^{*}$ Missing value is regarded as outcome not present.

†If infant died before 36 weeks, BPD status was treated as 'unknown'; if infant was discharged before 36 weeks, BPD status was treated as negative.

¥Mean (SE).

§Median (IQR).

BPD, bronchopulmonary dysplasia; NEC, necrotising enterocolitis; PN, parenteral nutrition; ROP, retinopathy of prematurity.

In this study babies were included from 2008 when practice had changed to commencing PN earlier. We tried to account for clinical condition on the first day by matching on various factors. There are likely to be other factors, not recorded in the study, that were different between the groups which we were unable to account for.

Our finding of evidence of greater morbidity in survivors who received early $\mathrm{PN}$ is in keeping with evidence in critically ill adults, children and term neonates, which has led to calls for the de-implementation of early PN in these groups. ${ }^{21}$ The mechanisms that explain the adverse outcomes in paediatric patients are equally likely to play a role in preterm infants. A secondary analysis of the PEPaNIC trial (The Early versus Late Parenteral Nutrition in the Pediatric Intensive Care Unit), comparing early versus delayed $\mathrm{PN}$ in critically ill children and babies, found that it was the early administration of amino acids, but not glucose or lipids, that explained the harm from early PN. ${ }^{22}$ The authors proposed several mechanisms, noting that amino acids are powerful suppressors of autophagy, and including the possibility that amino acid load exceeding anabolic capacity results in diversion to hepatic production of urea, supported by their findings of increased plasma urea during the intervention period. Early PN and amino acids were also implicated in the differential methylation of genes that are associated with brain development in another secondary analysis of the PEPaNIC trial. ${ }^{14}$ It might be argued that, in contrast to critically ill children and infants, not all preterm infants are critically ill after birth. However, metabolic disturbances and instability are common in the immediate postnatal period in very preterm infants. We have previously found that $50 \%$ of infants born $<31$ weeks gestation recruited to a trial of PN (commenced within 24 hours of birth) had hyperglycaemia (>15 mmol/L). Of all trial participants $40 \%$ had hypertriglyceridaemia $(>2 \mathrm{mmol} / \mathrm{L}){ }^{23}$ Hyperglycaemia and hypertriglyceridaemia are associated with increased mortality and morbidity in very preterm infants. ${ }^{24-26}$ In both arms of the same trial, 50\% developed blood urea levels $>7 \mathrm{mmol} / \mathrm{L}$, with $50 \%$ developing blood urea $>10 \mathrm{mmol} / \mathrm{L}$ in the high intake arm, suggesting intakes exceeding anabolic capacity with the current recommended intakes. Indeed, studies of higher intakes of macronutrients in very preterm babies in the early postnatal period are associated with other metabolic derangements, including the refeeding syndrome. ${ }^{27}$ The refeeding syndrome was found to be 
associated with a higher rate of sepsis in a study of enhanced compared with standard feeding. ${ }^{28}$ The preterm brain is especially susceptible to injury. Our data give cause for caution. Despite mortality of very preterm infants decreasing over the last two decades, with over $90 \%$ of infants surviving, long-term morbidity and neurodevelopmental outcomes have not shown similar improvements. ${ }^{29-32}$ The morbidities that we found significantly higher in those receiving early $\mathrm{PN}$ are those known to be associated with adverse long-term neurodevelopment. ${ }^{33-35}$

A large body of observational evidence in adults suggests improved survival with optimised energy and/or protein administration during critical illness. ${ }^{36-38}$ However, over 10000 patients evaluated in several randomised controlled trials of early and/or enhanced versus later and/or lower intakes showed no difference in mortality. ${ }^{63940}$ This marked difference between observational and interventional studies in relation to survival might suggest that adequacy of nutritional intake is a consequence of favourable clinical progression rather than its cause.

The strengths of our study are the large sample size, wholepopulation data and the use of propensity-matched analysis to balance a large number of baseline variables. The data are of high quality as the outcomes are included in the National Neonatal Audit Programme and are checked for accuracy by neonatal units. ${ }^{41}$ We addressed possible confounding by changes in nutritional practices over the 12 -year study period by matching infants on their year of birth. Infants were also matched on the level of unit and network of birth, thereby addressing possible confounding from unit-specific nutritional practices.

Our study has limitations. Despite matching for all baseline variables to ensure balanced groups, there may be residual unrecognised confounding from unobserved variables. This was a retrospective study using routinely recorded data that do not contain detailed information about nutritional intakes; thus, we could not match on such data. There was also a high degree of missingness for the 2-year outcome data and so we were unable to assess this outcome reliably. It is not possible to establish whether absence of an impairment being recorded was due to the child not attending follow-up or that the impairment was not present. When an impairment was missing, we assumed that it was not present. The rates of missing values recorded are around $70 \%$ in the early PN group and around $60 \%$ in the late PN group. It was not possible to establish the exact timing of initiation of PN in hours; only the postnatal day on which it was commenced was available. Therefore, the separation between the groups in the timing of initiation of PN is not wide and there is likely to be an overlap. We might expect any differences in outcomes to be even more pronounced with greater separation.

\section{CONCLUSION}

In this large, population-based, propensity-matched analysis of timing of initiation of PN in very preterm infants, we found no difference in morbidity-free survival. However, we found a significantly higher survival rate with early $\mathrm{PN}$ and higher rates of important morbidities. The observational nature of our study precludes drawing definitive conclusions that influence practice but provides justification for a randomised controlled trial, powered to study the safety (survival to discharge) as well as the efficacy (neurodevelopment) of early PN. There is also a need to explore subgroup effects and interactions based on gestational age, illness severity and physiological instability.

Twitter Sabita Uthaya @SabitaUthaya, Cheryl Battersby @DrCBattersby and Neena Modi @NeenaModi1
Acknowledgements We gratefully acknowledge the contribution of all UK Neonatal Collaborative neonatal units to the National Neonatal Research Database and Mr Richard Colquhoun, Research Manager.

Contributors SU: conceptualisation, study design, data interpretation, writing of original and final draft, access to and verification of data and guarantor. $\mathrm{NL}$ : methodology, data analysis and interpretation, figures, writing, review and editing, access to and verification of data. CB: data interpretation, writing, review and editing. $\mathrm{KO}$ and $\mathrm{JL}$ : data extraction and curation, review and editing, access to and verification of data. NM: data interpretation, writing, review and editing.

Funding The authors have not declared a specific grant for this research from any funding agency in the public, commercial or not-for-profit sectors.

Competing interests NM is the Chief Investigator for the National Neonatal Research Database at Imperial College London. SNU, NL, CB, KO and JL declare no conflict of interest involving the work under consideration for publication.

\section{Patient consent for publication Not required.}

Ethics approval The Health Research Authority and the Health and Care Research Wales approved the study (ID 273001).

Provenance and peer review Not commissioned; externally peer reviewed.

Data availability statement Data are available upon reasonable request.

Supplemental material This content has been supplied by the author(s). It has not been vetted by BMJ Publishing Group Limited (BMJ) and may not have been peer-reviewed. Any opinions or recommendations discussed are solely those of the author(s) and are not endorsed by BMJ. BMJ disclaims all liability and responsibility arising from any reliance placed on the content. Where the content includes any translated material, BMJ does not warrant the accuracy and reliability of the translations (including but not limited to local regulations, clinical guidelines, terminology, drug names and drug dosages), and is not responsible for any error and/or omissions arising from translation and adaptation or otherwise.

Open access This is an open access article distributed in accordance with the Creative Commons Attribution Non Commercial (CC BY-NC 4.0) license, which permits others to distribute, remix, adapt, build upon this work non-commercially, and license their derivative works on different terms, provided the original work is properly cited, appropriate credit is given, any changes made indicated, and the use is non-commercial. See: http://creativecommons.org/licenses/by-nc/4.0/.

\section{ORCID iDs}

Sabita Uthaya http://orcid.org/0000-0002-6112-2277

Neena Modi http://orcid.org/0000-0002-2093-0681

\section{REFERENCES}

1 NICE. Neonatal parenteral nutrition, 2020. Available: https://www.nice.org.uk/ guidance/ng154

2 Embleton NE, Pang N, Cooke RJ. Postnatal malnutrition and growth retardation: an inevitable consequence of current recommendations in preterm infants? Pediatrics 2001;107:270-3.

3 Ehrenkranz RA, Dusick AM, Vohr BR, et al. Growth in the neonatal intensive care unit influences neurodevelopmental and growth outcomes of extremely low birth weight infants. Pediatrics 2006;117:1253-61.

4 Moyses HE, Johnson MJ, Leaf AA, et al. Early parenteral nutrition and growth outcomes in preterm infants: a systematic review and meta-analysis. Am J Clin Nutr 2013;97:816-26

5 Leenders EKSM, de Waard M, van Goudoever JB. Low- versus high-dose and early versus late parenteral amino-acid administration in very-low-birth-weight infants: a systematic review and meta-analysis. Neonatology 2018;113:187-205.

6 Casaer MP, Mesotten D, Hermans G, et al. Early versus late parenteral nutrition in critically ill adults. N Engl J Med 2011;365:506-17.

7 Fivez T, Kerklaan D, Mesotten D, et al. Early versus late parenteral nutrition in critically ill children. N Engl J Med 2016;374:1111-22.

8 van Puffelen E, Polinder S, Vanhorebeek I, et al. Cost-effectiveness study of early versus late parenteral nutrition in critically ill children (PEPaNIC): preplanned secondary analysis of a multicentre randomised controlled trial. Crit Care 2018;22:4.

9 van Puffelen E, Vanhorebeek I, Joosten KFM, et al. Early versus late parenteral nutrition in critically ill, term neonates: a preplanned secondary subgroup analysis of the PEPaNIC multicentre, randomised controlled trial. Lancet Child Adolesc Health 2018;2:505-15.

10 Vanderheyden S, Casaer MP, Kesteloot K, et al. Early versus late parenteral nutrition in ICU patients: cost analysis of the EPaNIC trial. Crit Care 2012;16:R96.

11 Jacobs A, Dulfer K, Eveleens RD, et al. Long-term developmental effect of withholding parenteral nutrition in paediatric intensive care units: a 4-year follow-up of the PEPaNIC randomised controlled trial. Lancet Child Adolesc Health 2020;4:503-14.

12 Verstraete S, Verbruggen SC, Hordijk JA, et al. Long-term developmental effects of withholding parenteral nutrition for 1 week in the paediatric intensive care unit: a 
2-year follow-up of the PEPaNIC international, randomised, controlled trial. Lancet Respir Med 2019;7:141-53.

13 Verstraete S, Vanhorebeek I, van Puffelen E, et al. Leukocyte telomere length in paediatric critical illness: effect of early parenteral nutrition. Crit Care 2018;22:38.

14 Güiza F, Vanhorebeek I, Verstraete S, et al. Effect of early parenteral nutrition during paediatric critical illness on DNA methylation as a potential mediator of impaired neurocognitive development: a pre-planned secondary analysis of the PEPaNIC international randomised controlled trial. Lancet Respir Med 2020;8:288-303.

15 Verlinden I, Güiza F, Derese I, et al. Time course of altered DNA methylation evoked by critical illness and by early administration of parenteral nutrition in the paediatric ICU. Clin Epigenetics 2020;12:155

16 Gale C, Morris I. Neonatal data analysis unit steering B. the UK national neonatal research database: using neonatal data for research, quality improvement and more. Arch Dis Child Educ Pract Ed 2016;101:216-8.

17 Battersby C, Statnikov Y, Santhakumaran S, et al. The United Kingdom national neonatal research database: a validation study. PLOS One 2018;13:e0201815.

18 Battersby C, Longford N, Costeloe K, et al. Development of a gestational agespecific case definition for neonatal necrotizing enterocolitis. JAMA Pediatr 2017:171:256-63.

19 Imbens G, Rubin D. Causal inference for statistics, social, and biomedical sciences: an introduction. Cambridge: Cambridge University Press, 2015

20 Zhou Z, Rahme E, Abrahamowicz M, et al. Survival bias associated with time-totreatment initiation in drug effectiveness evaluation: a comparison of methods. Am J Epidemiol 2005:162:1016-23

21 van Puffelen E, Jacobs A, Verdoorn CJM, et al. International survey of Deimplementation of initiating parenteral nutrition early in paediatric intensive care units. BMC Health Serv Res 2019;19:379.

22 Vanhorebeek I, Verbruggen S, Casaer MP, et al. Effect of early supplemental parenteral nutrition in the paediatric ICU: a preplanned observational study of postrandomisation treatments in the PEPaNIC trial. Lancet Respir Med 2017:5:475-83.

23 Uthaya S, Liu X, Babalis D, et al. Nutritional evaluation and optimisation in neonates: a randomized, double-blind controlled trial of amino acid regimen and intravenous lipid composition in preterm parenteral nutrition. Am J Clin Nutr 2016;103:1443-52.

24 Stensvold HJ, Strommen K, Lang AM, et al. Early enhanced parenteral nutrition, hyperglycemia, and death among extremely low-birth-weight infants. JAMA Pediatr 2015;169:1003-10.

25 Sinclair R, Schindler T, Lui K, et al. Hypertriglyceridaemia in extremely preterm infants receiving parenteral lipid emulsions. BMC Pediatr 2018;18:348.

26 Zamir I, Stoltz Sjöström E, Ahlsson F. Neonatal hyperglycaemia is associated with worse neurodevelopmental outcomes in extremely preterm infants. Arch Dis Child Fetal Neonatal Ed 2021;106:460-6.
27 Cormack BE, Jiang Y, Harding JE, et al. Neonatal refeeding syndrome and clinical outcome in extremely low-birth-weight babies: secondary cohort analysis from the provide trial. JPEN J Parenter Enteral Nutr 2021;45:65-78.

28 Moltu SJ, Strømmen K, Blakstad EW, et al. Enhanced feeding in very-low-birth-weight infants may cause electrolyte disturbances and septicemia--a randomized, controlled trial. Clin Nutr 2013;32:207-12.

29 Santhakumaran S, Statnikov Y, Gray D, et al. Survival of very preterm infants admitted to neonatal care in England 2008-2014: time trends and regional variation. Arch Dis Child Fetal Neonatal Ed 2018;103:F208-15.

30 Costeloe KL, Hennessy EM, Haider S, et al. Short term outcomes after extreme preterm birth in England: comparison of two birth cohorts in 1995 and 2006 (the EPICure studies). BMJ 2012;345:e7976.

31 Burnett AC, Anderson PJ, Lee KJ, et al. Trends in executive functioning in extremely preterm children across 3 birth eras. Pediatrics 2018;141. doi:10.1542/peds.20171958. [Epub ahead of print: 0112 2017].

32 Cheong JLY, Anderson PJ, Burnett AC, et al. Changing neurodevelopment at 8 years in children born extremely preterm since the 1990s. Pediatrics 2017:139:e20164086.

33 Cheong JLY, Doyle LW. An update on pulmonary and neurodevelopmental outcomes of bronchopulmonary dysplasia. Semin Perinatol 2018;42:478-84.

34 Drost FJ, Keunen $\mathrm{K}$, Moeskops $\mathrm{P}$, et al. Severe retinopathy of prematurity is associated with reduced cerebellar and brainstem volumes at term and neurodevelopmental deficits at 2 years. Pediatr Res 2018;83:818-24.

35 Zonnenberg IA, van Dijk-Lokkart EM, van den Dungen FAM, et al. Neurodevelopmental outcome at 2 years of age in preterm infants with late-onset sepsis. Eur J Pediatr 2019;178:673-80.

36 Weijs PJM, Looijaard WGPM, Beishuizen A, et al. Early high protein intake is associated with low mortality and energy overfeeding with high mortality in nonseptic mechanically ventilated critically ill patients. Crit Care 2014:18:701.

37 Weijs PJM, Stapel SN, de Groot SDW, et al. Optimal protein and energy nutrition decreases mortality in mechanically ventilated, critically ill patients: a prospective observational cohort study. JPEN J Parenter Enteral Nutr 2012;36:60-8.

38 Alberda C, Gramlich L, Jones N, et al. The relationship between nutritional intake and clinical outcomes in critically ill patients: results of an international multicenter observational study. Intensive Care Med 2009;35:1728-37.

39 Heidegger CP, Berger MM, Graf S, et al. Optimisation of energy provision with supplemental parenteral nutrition in critically ill patients: a randomised controlled clinical trial. Lancet 2013;381:385-93.

40 Doig GS, Simpson F, Sweetman EA, et al. Early parenteral nutrition in critically ill patients with short-term relative contraindications to early enteral nutrition: a randomized controlled trial. JAMA 2013;309:2130-8.

41 RCPCH. National neonatal audit programme (NNAP). 2019, 2020. 